\title{
The age of criminal responsibility and the age of consent: should they be any different? \\ JONATHAN HERRING* \\ University of Oxford
}

\begin{abstract}
This article considers the connection between the age of criminal responsibility and the age at which a person is able to give effective consent. It argues that there a good reasons why these two ages could be different. In considering this issue the article looks at the concepts of criminal responsibility and consent within the criminal law. It claims that these involve assessment of very different factors. It could, therefore, be entirely appropriate for a court to determine that a child has sufficient legal capacity to be guilty of a criminal offence, but lack capacity to consent to behaviour that would otherwise be a criminal offence.
\end{abstract}

\section{Introduction}

B ill and Ben, both aged 12, have been friends since they met in the reception class of B primary school. One sunny afternoon they kiss. They have committed a criminal offence. ${ }^{1}$ Under the law in Northern Ireland and England both are over the age of criminal responsibility but under the age at which they can consent to a sexual activity. To many commentators that is bizarre. How can a person be mature enough to be responsible in the criminal law for their actions, but not mature enough to be able to give an effective consent to an otherwise criminal act?

Lyons has argued that the age of criminal responsibility should match the age at which children have capacity to make decisions in other contexts. Using the example of making medical decisions, he argues that if 'children are to be held accountable by the criminal justice system then it seems that we should recognize their capacity to make their own healthcare decisions'. ${ }^{2}$ He goes on to suggest it is incoherent for the law to 'perceive the views and actions of minors as reflective of immaturity for some legal purposes but of full agency for others'. ${ }^{3}$ He refers to the Standard Minimum Rules for the Administration

* Professor of Law, DM Wolfe-Clarendon Fellow in Law, Exeter College.

1 Sexual Offences Act 2003, s 7. It is true they may well not be prosecuted: Home Office, Guidance on the Sexual Offences Act 2003 (Home Office 2003) para 72, states: 'Although the age of consent remains at 16, the law is not intended to prosecute mutually agreed sexual activity between two young people of a similar age, unless it involves abuse or exploitation.' For a detailed discussion and criticism of the child sex offences in the Sexual Offences Act 2003, see John Spencer, 'Child and Family Offences’ [2004] Criminal Law Review 347.

2 Barry Lyons, 'Dying to be Responsible: Adolescence, Autonomy and Responsibility' (2010) 30 Legal Studies 257, 278.

3 Ibid 276. 
of Juvenile Justice (the Beijing Rules) ${ }^{4}$ which state that there is 'a close relationship between the notion of responsibility for delinquent or criminal behaviour and other social rights and responsibilities'. 5

To similar effect, Cipriani has argued that criminal responsibility should be seen as an aspect of children's rights:

Children's criminal responsibility is indeed an integral and necessary part of children's rights - a logical extension of the concept of children's evolving capacities insofar as it is an appropriate step in respecting children's progression from lesser to greater competence, which gradually prepares them for adult rights and responsibilities. ${ }^{6}$

Such academic arguments ${ }^{7}$ are reflected in parliamentary debates. For example, Lord Dholakia claimed, during a debate in the House of Lords on raising the age of criminal responsibility:

It cannot be right to deal with such young children in a criminal process based on ideas of culpability which assume a capacity for mature, adult-like decisionmaking. There is no other area of law - whether it is the age for buying a pet, the age for paid employment, the age of consent to sexual activity or the age for smoking and drinking - where we regard children as fully competent to take informed decisions until later in adolescence. The age of criminal responsibility is an anomalous exception. ${ }^{8}$

In this article, I will respond to such arguments and attempt to justify why the law might, quite properly, have a different age for criminal responsibility from the age for capacity to consent to something that would otherwise be a criminal offence. I will focus on the capacity to consent to sex as an example because, as the hypothetical of Bill and Ben demonstrates, that illustrates particularly well the apparent inconsistency in the law.

I will not seek to justify the particular ages used in the current law. In fact, I believe the current age for criminal responsibility is much too low, but it is not the purpose of this article to make that particular argument. ${ }^{9}$ Nor is it my argument that the age of criminal responsibility and the age of capacity to consent to sex must necessarily be different. I fully accept that, taking into account the factors referred to in this article, a reasonable person might conclude that the same age should be used for both. Rather, my purpose in this article is to demonstrate that the factors that should be considered in determining an age for criminal responsibility are very different from those that are relevant in fixing the age at which a person can give legal effective consent. These could, quite reasonably, lead someone to conclude that there be markedly different ages for criminal responsibility and for capacity to consent.

4 Ibid 276.

5 UN, United Nations Standard Minimum Rules for the Administration of Juvenile Justice (UN 1985).

6 Don Cipriani, Children's Rights and the Minimum Age of Criminal Responsibility: A Global Perspective (Ashgate 2009) 34 .

7 Niklas Juth and Frank Lorentzon, 'The Concept of Free Will and Forensic Psychiatry' (2010) 33 International Journal of Law and Psychiatry 1.

8 HL Deb 8 November 2013, vol 749, col 477.

9 I explore issues around the age of consent in detail in Jonathan Herring, 'Age of Consent in an Age of Consent' in Chris Ashford, Alan Reed and Nicola Wake (eds), Consent and Control: Legal Perspectives on State Power (Cambridge Scholars 2016). 


\section{The current position on age of consent and age of responsibility}

The age for criminal responsibility in Northern Ireland and England is 10. In Scotland it is 8, although for those under the age of 12 there are special children's hearings. According to Keating, the average age of criminal responsibility around Europe is 14, with Denmark, Finland, Norway and Sweden opting for an age of criminal responsibility at $15 .{ }^{10}$ Among academic writers there is widespread agreement that the current law of criminal responsibility in the UK is too low. ${ }^{11} \mathrm{I}$ have not found a single academic lawyer's writing which seeks to support the current age of 10 . It is certainly out of kilter with the general approach taken worldwide. ${ }^{12}$ The UN Committee on the Rights of the Child ${ }^{13}$ states: 'a minimum age of criminal responsibility below the age of 12 years is considered by the Committee not to be internationally acceptable'. It goes on to recommend, however, that states that have already set a higher minimum age should not lower it to 12 because a higher minimum age of around $14-16$ years is preferable. ${ }^{14}$

Historically, the age of consent to sex has varied significantly. It was 10 in 1576, but increased to 14 in the late nineteenth century. The late Victorian age, with the concerns about child prostitution, saw the Criminal Law Amendment Act 1885 raise the age for girls to 16. The age for male same-sex behaviour was lowered from 21 to 18 in 1994 and from 18 to 16 to produce equality between homosexual and heterosexual sex in the Sexual Offences (Amendment) Act 2000. ${ }^{15}$ The Sexual Offences Act 2003, includes a wide range of offences in relation to children. Generally, it relies on 16 as the age at which children can give effective consent to sexual behaviour. There is much more that could be said about the details in this area of the law, but that is not the primary focus of this article. ${ }^{16}$

\section{Key argument}

The article argues that questions about criminal responsibility are fundamentally different from questions about capacity to consent. Criminal responsibility is about determining the extent to which a person is responsible for their own actions before a criminal court and is a suitable candidate for punishment. It is no requirement of a criminal law that an individual be wholly responsible for the harm to the victim, otherwise prisons would be largely empty. It is sufficient if a person is responsible enough to be held accountable for their actions.

By contrast, consent is giving another person justification to do an act which is otherwise wrongful. The law understandably is reluctant to allow a person (D) to do an act which is prima facie wrongful to another (V), unless there are sufficiently good reasons for doing so. Consent, in some cases, can provide that good reason. However, flaws in V's consent may well render that consent insufficient to justify D's act. D, in the face of an inadequate consent, should not proceed to harm V.

So, the key point is that asking whether an individual with impaired capacity is responsible for their own action is very different from asking whether the consent of an

10 Heather Keating, 'Children's Rights and Children's Criminal Responsibility' in A Diduck, N Peleg and H Reece (eds), Law in Society (Brill 2015).

11 Ibid 295.

12 Neal Hazel, Cross-National Comparison of Youth Justice (Youth Justice Board 2008).

13 UN Committee on the Rights of the Child, General Comment No 10 (UN 2007) para 32.

14 Ibid para 33.

15 See Sarah Beresford, 'The Age of Consent and the Ending of Queer Theory' (2014) 4 Laws 759, for further discussion.

16 Herring (n 9). 
individual with impaired capacity is able to give effective justification to another for a wrong done against them. Before exploring that further we need to discuss the ways in which children's capabilities may be said to be different from those of adults.

\section{Children's inabilities}

It is widely accepted that there are significant differences generally speaking in the capabilities of children and adults. The Beijing Rules state that the minimum age 'shall not be fixed at too low an age level bearing in mind the facts of emotional, mental and intellectual maturity'. ${ }^{17}$ The Royal College of Psychiatrists ${ }^{18}$ and Royal Society ${ }^{19}$ agree that the age of 10 is too low for criminal responsibility:

... it is clear that at the age of ten the brain is developmentally immature and continues to undergo important changes linked to regulating one's own behaviour.

There is ample evidence to show that children, as compared with adults, generally have limited understanding of facts, are impressionable and suggestible, and have more limited powers of reasoning. ${ }^{20}$ Vilojoen, Penner and Roesch argue ${ }^{21}$ that adolescents have lower abilities to appreciate the long-term consequences of their decisions. Indeed, they claim that, although it used to be assumed that the cognitive functioning of people in midadolescence was comparable to adults, in fact brain development continues until one's early twenties. There is also good evidence of adolescence indicating a time of increased impulsivity and sensation-seeking. ${ }^{22}$

Adolescents, generally, have a more limited ability to empathise than adults and are more vulnerable to peer influence. ${ }^{23}$ Elliott $^{24}$ highlights the ways in which children are impacted by external factors to a far greater extent than adults:

... in looking at criminal responsibility we need to be prepared to take into account the social reality of a child's personal experiences, including bad parenting, poverty and violence, rather than trying artificially to ignore these factors. These factors can reasonably be taken into account with regard to children's liability because with their limited capacity they do not have a genuine opportunity to make a choice as to how they behave; the impact of these external factors becomes determinative of their behaviour since children are not autonomous individuals. This lack of autonomy is reflected in the striking research results showing the strong correlation between poor parenting, poverty, abuse and youth offending.

For the purposes of this article, I will take it that such claims are well made and that in these various ways children's understanding and reasoning abilities are more limited than

17 UN General Assembly, United Nations Standard Minimum Rules for the Administration of Juvenile Justice (A/RES/40/33 UN 2005).

18 Children Defendants (Occasional Paper No 562996 Royal College of Physicians 2006).

19 Royal Society, Neuroscience and the Law (Royal Society 2011) 14.

20 Jodi Viljoen, Erika Penner and Ronald Roesch, 'Competence and Criminal Responsibility in Adolescent Defendants: The Roles of Mental Illness and Adolescent Development' in Donna Bishop and Barry Feld (eds), The Oxford Handbook of Juvenile Crime and Juvenile Justice (OUP 2011).

21 Ibid.

22 Enys Delmage, 'The Minimum Age of Criminal Responsibility: A Medico-Legal Perspective' (2013) 13 Youth Justice 102.

23 Jennifer Drobac and Leslie Hulvershorn, 'The Neurobiology of Decision Making in High-Risk Youth and the Law of Consent to Sex’ (2014) New Criminal Law Review 502.

24 Catherine Elliott, 'Criminal Responsibility and Children: A New Defence Required to Acknowledge the Absence of Capacity and Choice' (2011) 75 Journal of Criminal Law 289, 297. 
those of adults. ${ }^{25}$ What is the significance of that for matters of criminal responsibility and age of consent?

\section{The essence of criminal responsibility}

What is the basis upon which children are given an exemption from criminal liability? McDiarmid's summary captures the views of many on what state of mind generally is required before criminal responsibility can attach to an act:

... fair imputation of criminal responsibility requires understanding of a number of interlinked concepts, including knowledge of wrongfulness, understanding of criminality and its consequences and an internalized moral appreciation of the quality of the conduct. ${ }^{26}$

This needs some unpacking. First, note that criminal capacity is not simply about understanding facts; it is about being able to use those facts to make decisions. Hart explained:

What is crucial is that those whom we punish should have had, when they acted, the normal capacities, physical and mental, for doing what the law requires and abstaining from what it forbids, and a fair opportunity to exercise these capacities. Where these capacities and opportunities are absent . . . the moral protest is that it's morally wrong to punish because 'he could not have helped it', or 'he could not have done otherwise' or 'he had no real choice'. ${ }^{27}$

Second, there is more to criminal responsibility than understanding and using the information to make a decision. The individual must have a set of beliefs and values they can apply to assess the decision made. Tadros explains:

First, she must have a coherent set of beliefs and, for the most part, those beliefs must be true. Second, she must recognise a reasonably broad range of forms. She must recognise the value of at least a broad range of things that are valuable, such as liberty, equality, personal security, truth, knowledge, and so on. Third, the agent must be capable of realising her beliefs and evaluations in action. And this includes the capacity to develop and execute reasonably complex plans of actions. $^{28}$

These requirements are not, however, meant to set a very high standard. Even though a person may be somewhat mistaken about their actions or have a mild intellectual impairment, they may legitimately be held to account for what they have done. We can see this by the fact that the defendant had 'lost their self-control' at the time of the offence is not generally a defence and, when it is, it remains only a defence to murder in limited circumstances. ${ }^{29}$

The general criminal law, however, recognises that, even with the bar of responsibility set relatively low, some defendants will lack the necessary capabilities. That is why we have the mens rea requirements and defences in the criminal law. Are these not adequate for children? Horder explains why they are:

25 Although see Jonathan Herring, 'Vulnerability, Children and the Law' in Michael Freeman (ed), Law and Childhood Studies (OUP 2012).

26 Claire McDiarmid, ‘An Age of Complexity: Children and Criminal Responsibility in Law' (2013) 13 Youth Justice 145.

27 Herbert Hart, Punishment and Responsibility: Essays in the Philosophy of Law (Clarendon Press 1968) 152.

28 Victor Tadros, Criminal Responsibility (OUP 2005) 137.

29 Coroners and Justice Act 2009, ss 54-55. 
... in a civilised legal system, only those who have the intellectual and moral capacity to understand the significance of their conduct will fall to be judged under its rules of criminal responsibility. Lacking such a capacity, under-age children and the insane are excluded from judgement and these rules, and the law's commands are not addressed to them ...30

This indicates that in relation to children it is not a claim that at the time of the offence they were not criminally responsible, in the way an adult who raises a defence argues. Rather in the case of children their status is such that they are not generally subject to the supervision of the criminal law. To justify criminal responsibility not only must there be the act of a will, that act must be an 'expressions of characters that come from us or that at any rate are acknowledged and affirmed by us', as Wolf puts it. ${ }^{31}$ This is something that children have not yet developed the capacity to do. For most adults their behaviour can legitimately be said to reflect their character, although excuses can be appropriate for the unusual circumstances in which it does not. For children, generally their behaviour does not reflect their character.

To be the proper subject of the criminal law requires not just intellectual capacity, but a moral capacity to understand and engage with the legal rules. Tadros explains:

Exemptions have commonly been understood in relation to the communicative aspect of the criminal justice system. The criminal law aims to communicate through its norms. But there are those who do not understand the norms of the criminal law. The criminal law, it might be argued, does not communicate with those who do not understand it. And consequently those who do not understand the criminal law cannot be held responsible by the criminal justice system. The norms of the criminal law, it is argued, are not addressed to them. ${ }^{32}$

It should be seen from this brief discussion that the exemption of the criminal law in relation to children is about more than assessment of capacity. It is about whether children are properly the subject of the criminal law: whether they are able to understand the norms promoted by the criminal law; be held to account for breach them; and engage in the criminal trial. As we shall see this is very different from what we are looking at in terms of the age of consent.

\section{The essence of consent}

What are we looking for when determining age of consent? Key to answering that question is an assessment of 'how consent works'. The model of consent I will adopt here is that propounded by Madden Dempsey. ${ }^{33}$ In outline the approach is as follows: consent is only needed when D's act is wrongfully harming another person's well-being, thereby rendering the act a prima facie wrong. That means that $\mathrm{D}$ must provide a justifying reason for acting in the way they did. Consent can provide that justifying reason. It does this by allowing $\mathrm{D}$ (if they wish) to assume that if $\mathrm{V}$ consents that the act is not all things considered contrary to V's well-being. That is because D is permitted to rely on V's assessment of their own best interests. In effect where consent is effective Madden Dempsey claims that $\mathrm{D}$ is entitled to say:

30 Jeremy Horder, 'Criminal Law: Between Determinism, Liberalism and Criminal Law' (2006) 49 Current Legal Problems 159, 167-68.

31 Susan Wolf, 'Sanity and the Metaphysics of Responsibility' in Ferdinand Schoeman (ed), Responsibility, Character and the Emotions (CUP 1987) 50

32 Tadros (n 28) 136.

33 Michelle Madden Dempsey, 'Victimless Conduct and the Volenti Maxim: How Consent Works' (2013) 7 Criminal Law and Philosophy 11. 
This is [V]'s decision. He's an adult and can decide for himself whether he thinks the risk is worth it. In considering what to do, I will assume that his decision is the right one for him. After all, he is in a better position than I to judge his own well-being. And so, I will not take it upon myself to reconsider those reasons. Instead, I will base my decision of whether to [harm] him on the other relevant reasons. 34

This model provides a helpful explanation of what we are looking for with consent: that it gives D sufficient reason to rely on V's assessment of V's well-being. Where D knows that V's apparent consent is flawed, for example, it is based on a mistake, or is a result of significant pressure, then $\mathrm{D}$ cannot rely on it. Further, $\mathrm{D}$ has a responsibility to ensure that $\mathrm{V}$ is in the position to make a proper assessment of their own well-being.

\section{Differences}

We can now start to see some of the reasons why there might be a difference between the features of criminal responsibility and age of consent. These include the following:

\section{ISSUE-SPECIFIC CAPACITY VERSUS GENERAL CAPACITY}

The first point to emphasise is that the criminal law age of responsibility is making a general assessment of responsibility for all crimes. Once one has reached the age of 10 , one can be convicted of any offence. Capacity to consent is, however, issue specific. That is true for adults, as well as children. Someone may have the understanding and maturity to choose what to eat for dinner, but lack the abilities to sign a will. Hence, it is not surprising that the law grants children the capacity to engage in different activities at different times. True, this leads to some bizarre outcomes: a 16-year-old can consent to sex with their MP before they are legally entitled to vote for him; but that probably indicates the voting age is set too high, rather than there is some fundamentally problematic notion with different ages of consent being used for different activities.

It is, therefore, perfectly sensible for the law to have one age at which a person is generally responsible for all crimes and a different one at which a person has capacity to consent to a particular activity, such as sex. That argument is likely to mean one would have a higher age of criminal responsibility than an age of consent for some activities, especially more straightforward ones.

\section{MISTAKES}

Second, generally in the criminal law a mistake about the factual situation in which one is acting will only impede responsibility insofar as it relates to an aspect of the mens rea of a crime. For example, if someone is charged with criminal damage of property belonging to another and relies on a claim that they thought they were breaking a pen and did not realise that in fact it was an electronic gadget, they will have no kind of a defence. Only a mistake which related to the elements of the actus reus would be relevant: for example, whether the thing was property; whether the thing belonged to another. This is because it is for the state to define the essential aspects of the wrong of an offence. It is not for the offender to decide what they think is important about a crime. To them, for example, breaking a pen might be very different to breaking an electronic gadget, but for the state that is not a difference of significance to the definition of criminal damage; and they are properly convicted regardless of their mistake. 
By contrast, in the case of consent, we are, as argued earlier, focusing on V's assessment of their well-being. So if $\mathrm{V}$ believes a fact is of central significance to their decision to consent, then there will be no consent if that is not provided because $\mathrm{V}$ will not have made an effective assessment of whether the act is in their best interests. If, to use an example from the case law, $\mathrm{V}$ consented to sex as long as $\mathrm{D}$ wore a condom and $\mathrm{D}$ did not; $\mathrm{D}$ could not rely on V's consent, because $\mathrm{V}$ had not determined that sex without a condom was in their best interests. ${ }^{35} \mathrm{It}$ is not for the state to determine what issues are important to consent, $\mathrm{V}$ can determine that for herself.

An example may clarify this point. If there is an Islamophobic 13-year-old who believes all people who wear turbans are Muslims and assaults a non-Muslim turbanwearing victim, believing him to be a Muslim, he can readily be convicted of having committed a crime. His mistake is irrelevant to what the state believes is significant about the wrong of an assault. By contrast if the Islamophobic 13-year-old consents to sex with a Muslim man who promises he is not Muslim (when she would not have consented had she known he was Muslim), that mistake is key. It is for her to decide what is important about sex and, if to her the religion of her partner is key, her mistake negates consent. As these scenarios show, the mistake in relation to conviction would be irrelevant, but for the consent case it could be crucial.

\section{THE ROLE OF VALUES}

Third, as mentioned earlier, for criminal responsibility the defendant must be able to engage with the criminal law and the values it seeks to promote. ${ }^{36}$ The whole aim of the criminal law is to set standards which are sufficiently clear and can direct a defendant's behaviour. The justification for punishment by the criminal law is that the defendant should have known what was expected of the criminal law and amended their behaviour accordingly. By contrast, for age of consent the issue is rather whether an individual is able to develop their own values and be in a position to determine what is in their wellbeing. One must have values, values which one has adopted as one's own, and be able to apply the information one has to these values. ${ }^{37}$

The distinction I am drawing here is about being in a position to understand the norms of society (which is essential to be responsible under criminal law) and being in a position to develop one's own values, in order to have the ability to make an assessment of one's well-being to be able to consent. ${ }^{38}$ It may well be that children, through the education system, will develop more quickly an awareness of the rules of society, than the kind of self-knowledge needed to adopt their own values.

\section{RESPONSIBILITY FOR LIMITS IN RESPONSIBILITY}

Fourth, a person may be responsible in the criminal law if they lack responsibility through their own fault, for example, through drunkenness. Even if a defendant lacks full responsibility at the time of committing the crime, if they are to be blamed for putting themselves in that position, criminal liability might justifiably be attached. But, the situation is very different in a case of consent. If $\mathrm{D}$ wishes to harm a drunken $\mathrm{V}, \mathrm{D}$ cannot say 'it is V's fault she is unable to consent'. D must simply refrain from harming

35 Assange v Swedish Prosecution Authority [2011] EWHC 2849.

36 Thomas Crofts, 'Catching up with Europe: Taking the Age of Criminal Responsibility Seriously in England' (2009) 17 European Journal of Crime, Criminal Law and Criminal Justice 267.

37 Jonathan Herring and Jesse Wall, 'Capacity to Consent to Sex' (2015) 22 Medical Law Review 620.

38 Jillian Craigie, 'Against a Singular Understanding of Legal Capacity: Criminal Responsibility and the Convention on the Rights of Persons with Disabilities' (2015) 40 International Journal of Law and Psychiatry 6. 
V, or find a justification other than consent. In short, a drunken D can be held responsible for their limitations in their capacity for which they are responsible; but they cannot rely on the consent of $\mathrm{V}$ who lacks capacity, even if $\mathrm{V}$ may be blamed for that.

\section{ENGAGEMENT IN TRIAL}

Fifth, a central aspect of capacity required for criminal responsibility is that the individual may be able to participate in the trial. Duff argues that this requires, at least, that the person can reason to the degree that we can address them as fellow participants in the trial. ${ }^{39}$ For Duff, and other criminal theorists, this potential to engage with the trial (and arguably with the punishment that follows) is an essential aspect of criminal responsibility. This may require skills and maturity that differ from issues relating to capacity to consent.

So far we have been looking at the kind of factors which the law might take into account in determining whether a child has capacity to have criminal responsibility or consent and we have seen these are very different and so it would be unsurprising if they led to different ages being selected. However, we have been assuming that we should be selecting an age. This assumption must be questioned.

\section{Bright lines and the use of age}

The criminal law inevitably draws bright lines. That is, in part, because the rule of law requires that the criminal law be clearly defined so that a person can know in advance whether their proposed conduct will be a criminal offence or not. ${ }^{40}$ Imagine a law which said it was an offence 'to drive at too fast a speed'. This would clearly seem to breach the rule of law requirement. A driver would not know in advance what speed a court might deem to be fast. A clearly set speed limit, say $30 \mathrm{mph}$, offers clear guidance as to what speed is regarded too fast. That example provides us with another clear benefit of such a bright line which is ease of proof. A court can easily resolve a case about whether a car was driving over $30 \mathrm{mph}$ with appropriate technology. A case of 'driving at too fast a speed' could take a considerable amount of time to resolve.

Of course, such bright-line rules have a serious drawback. They can operate in a way which in some cases may seem over-protective. Imagine a person is driving at $35 \mathrm{mph}$ in a $30 \mathrm{mph}$ zone and can show that given their extraordinary driving abilities, the weather conditions and lack of other vehicles or pedestrians their driving was, in fact, safe. They would nevertheless have committed the offence. Perhaps more plausible, a driver may be driving at $26 \mathrm{mph}$, and so commit no offence, but might in all the circumstances not be driving at a safe speed. They would, nevertheless, be entitled to be acquitted of the speeding offence. In short, the clarity and efficiency of the bright line comes with 'errors' on either side of it. ${ }^{41}$

These arguments apply too in relation to age of consent. No one will pretend that at, say, midnight on their 16th birthday the teenager magically acquires the knowledge and maturity to be treated as an adult. Rather the age of consent provides a bright-line determination. Baroness Hale in $\mathrm{R} v G$ explained:

39 Antony Duff, 'Law, Language and Community: Some Preconditions of Criminal Liability' (1989) 18 Oxford Journal of Legal Studies 189.

40 Joseph Raz, The Authority of Law (OUP 1979) ch 1.

41 Jonathan Herring, 'Children's Rights for Grown Ups' in Sandra Fredman and Sarah Spencer (eds), Age as an Equality Issue (Hart 2003). 
Even if a child is fully capable of understanding and freely agreeing to such sexual activity, which may often be doubted, especially with a child under 13, the law says that it makes no difference. He or she is legally disabled from consenting. ${ }^{42}$

As she emphasises, with such a legal presumption there is no claim that every child under a particular age in fact has capacity to consent (although she may well), but rather that there are sound policy reasons for conclusively presuming that not to be so. Similarly, in relation to the age of criminal responsibility, the current law draws a bright line. However, are age of consent and age of criminal responsibility good examples of where a bright line is needed?

I suggest that line-drawing of this kind with age requires us to consider the following:

1 Is this a situation which is better resolved by individual assessment in the particular circumstance, rather than drawing a line?

2 At what age should the line be drawn?

It is in response to the two questions outlined that there is a clear difference in the issues raised by age of consent and age of criminal responsibility.

\section{Individual assessment or bright line?}

Consider, first, age to consent to sexual offences. In English law, for example, a child who is below the age of 16 can give effective consent to receive medical treatment, if she is able to persuade a doctor that she has sufficient maturity to understand the issues raised (Gillick competence, as it is known). ${ }^{43}$ Fairly obviously, we could not take the same approach to a defendant wishing to have sex with a child. While a doctor may have the expertise, detachment and time to make such an assessment, a would-be sexual partner does not. Duff ${ }^{44}$ explains that there are certain dangerous activities where people cannot be trusted and should not trust themselves to decide whether the activity is safe. He writes:
A man excited at the prospect of sex with a young woman is ill placed to judge her maturity; a driver in a hurry is ill placed to judge how fast it is safe for her to drive; and someone relaxing in a pub is ill placed to judge whether another drink might impair his capacity to drive safely. We recognise the need for some kind of regulation in these spheres, because we cannot trust each other, or ourselves, to decide in these contexts whether we can safely engage in a proposed action (having sexual intercourse with this young person; driving at this speed, or after having this many drinks). ${ }^{45}$

He says of a defendant who insists that their underage partner has capacity: 'he does not know that he knows this' and if he goes ahead based on his own judgement he takes an unjustified risk, he is wrong, and:

... arrogantly claims the right to decide for himself on matters which he, like the rest of us, should not trust himself to decide. His claim is arrogant because it is unjustified - but also because it seeks to set him above his fellow citizens, in matters which affect their legally protected interests; and that is what merits the censure of the criminal law. ${ }^{46}$

$42 R v G[2008]$ UKHL 37 (HL), [44].

43 Ibid.

44 Antony Duff, 'Crime, Prohibition, and Punishment' (2002) 19 Journal of Applied Philosophy 97.

45 Ibid 103.

46 Ibid. 
These arguments point strongly in favour of having a bright-line age, chosen by the law.

Can we make the same argument about the age of criminal responsibility? I would argue not. We have an opportunity to assess the capacity of the child in the courtroom and use expert evidence to assist the court in that assessment. This was regularly done when we had the defence of doli incapax. A child between the age of 10 and 14 was presumed to be doli incapax, ${ }^{47}$ but that could be rebutted if it was shown at trial that the child knew the difference between something being seriously wrong or merely 'naughty'. ${ }^{48}$ That may or may not be the right question, but it shows that the court could make this kind of independent assessment. The grounds for using an individualised assessment are particularly strong given that the consequences of the decision are serious.

\section{Factors in assessing the appropriate age}

If we assume for the moment that a bright line of age is required for both age of consent and criminal responsibility (so that the arguments just made are rejected), how do we select the appropriate age? Of course, the factors we have discussed earlier about when children generally have the kinds of capacity needed for criminal responsibility or to give effective consent will be considered. However, there is another relevant issue and that is the severity of the errors where the age is wrongly placed.

Let us imagine (and these figures are simply hypothetical) that we are persuaded that at the age of 13: 25 per cent of children have capacity to consent to sex and to be held accountable for criminal acts and 75 per cent do not; at 14, 45 per cent do and 55 per cent do not; at 15, 75 per cent do and 25 per cent do not; and at 16, 98 per cent do and 2 per cent do not. ${ }^{49}$ Which proxy should be selected? Should we choose (on my figures) 15 because by then it will be correct in the majority of cases?

I argue that the balance of the arguments could, potentially, fall differently for the capacity to consent to sex and for the responsibility argument. Choosing the appropriate age requires weighing up the wrong done to those deemed to have capacity to consent/have responsibility for criminal law, who in reality do not; and the wrong done to those deemed not to have capacity to consent/be criminally responsible, who in reality do. They are not equal.

Take, first, the issue of consent to sex. Consider those deemed not to have capacity, but in fact do. There will, then, be an interference in their private life. Anyone who has sex with them will be treated as committing a criminal offence. This may mean that there will be people who will not be able lawfully to have the sexual encounter they wish, because of the legal provision. Of course, this will not be true for all those with capacity under the designated age. They may not wish to engage in sex, or may not be able to find a partner. So not all those with capacity will have their rights effectively interfered with. Even for those who do, the interference is limited in that it will cease once they reach the age of consent. ${ }^{50}$

Consider, next, those who might be deemed to have capacity, but in reality will lack it. The law will be failing to protect their rights in a major way. In part this is an

47 The doli incapax defence was abolished in 1998 by the Crime and Disorder Act 1998, s 34 (R $v$ JBT [2009] 1 AC 1310).

$48 \mathrm{R} v$ Gorrie (1919) 83 JP 136.

49 Of course, it is highly simplistic to suggest capacity is straightforwardly something you do or do not have.

50 See E $v$ DPP [2005] EWHC 147, where a law prohibiting two 15-year-olds from engaging in sexual relations with each other was not seen as a breach of their human rights. For further discussion, see Diane Richardson, 'Constructing Sexual Citizenship: Theorizing Sexual Rights' (2000) 62 Critical Social Policy 105. 
acknowledgment that the law of rape, generally, is not efficient in protecting victims from rape and an age-based statute will provide a stronger deterrent and easier route for prosecution of those who have sex with the non-consenting child under the age of consent.

The harm done to a group assessed as having capacity when in fact they do not is far greater than the group assessed as lacking capacity when in fact they do. The former are put at risk of rape, the latter at risk having to put off lawful sexual experiences for a short time. We should be far happier to err on the side of deeming the competent incompetent than of deeming the incompetent competent. ${ }^{51}$

What about a similar analysis in terms of age of responsibility? The arguments above do not play out in the same way. That is because in the case of 'errors' both ways the balancing is different. First, the issue of 'waiting' to acquire their legal responsibility is not relevant in this context. Second, because where a child in fact has the capacity to be criminally responsible, but is not treated as criminally liable, it is hard to see how there is any interference in their rights at all. Hollingsworth states: 'conferring criminal responsibility on the child, even where he may lack actual capacity, can be seen as giving effect to the child's autonomy rights'. ${ }^{52}$ While at a theoretical level one might see acknowledging responsibility as a way of respecting autonomy, it is a problematic view in two ways. First, respecting the decisions of a person who lacks capacity is not promoting their autonomy. ${ }^{53}$ Second, subjecting a child to the ministrations of the criminal justice rarely promotes autonomy. At least, it is hard to see how it is likely to do so more than other social interventions concerning behaviour might do. There is no reason why, considering the consequences of these errors, the arguments over where to pitch the age of consent and age of criminal responsibility could be placed at different places.

\section{Social factors}

So far much of the discussion has been in terms of the issues relating to the individual child. However, the issues at hand have broader social impact. Yet again, these play out differently in relation to the two questions.

Several points can be made. The first is that social factors have impact based upon the kind of values that we as a broader society seek to promote. As Craigie argues:

Rather, the boundary between mental capacity and incapacity in the private sphere is drawn in part on the basis of moral and political commitments such as the value of liberty, well-being and life. These considerations shape what is considered minimally necessary in terms of mental functioning for the legal capacity to make one's own personal decisions. As a result, different societies, or the one society at different times, will draw this line in different places on the basis of divergent evaluative commitments. ${ }^{54}$

She goes on to explain:

In law concerning personal decisions, a choice must be made between prioritizing liberty by recognizing legal capacity, or protecting well-being. But in law concerning criminal responsibility there is a different choice to be made. In this context, by erring on the side of recognizing legal capacity one avoids the

51 For a broader examination of this argument, see Stephen Gilmore and Jonathan Herring, 'No is the Hardest Word: Consent and Children's Autonomy' (2011) 23 Child and Family Law Quarterly 3.

52 Katherine Hollingsworth, 'Responsibility and Rights: Children and their Parents in the Youth Justice System' (2007) 21 International Journal of Law, Policy and the Family 190.

53 Jonathan Herring and J Wall, 'Autonomy, Capacity and Vulnerable Adults: Filling the Gaps in the Mental Capacity Act' (2015) Legal Studies 698.

54 Craigie (n 38) 12. 
risk of excusing someone and diverting them out of the criminal justice system (or holding them responsible for a less serious offence) when they should in fact be held fully responsible. The risk that is preferred is the punishment of people who should be diverted out of the criminal justice system. Whether this seems like the right risk to choose rests on a judgement about the relative seriousness of these outcomes. 55

Second, there are clearly different public policy factors at play. An obvious example might be that, if children were causing serious harms to others in society, there would be a public interest in ensuring victims were protected from these harms. One response could be by using criminal liability. We might alternatively believe that subjecting young people to the criminal process at a young age will increase the chance of their offending in the future and therefore the age of responsibility should be increased. ${ }^{56}$ Similarly, in relation to age of consent laws, it might be argued that the social costs of teenage pregnancy would justify a higher age of consent. Baroness Hale in $\operatorname{Re} G^{57}$ commented:

In view of all the dangers resulting from under-age sexual activity, it cannot be wrong for the law to apply that label [rape] even if it cannot be proved that the child was in fact unwilling.

I do not suggest these arguments should be persuasive (there is, for example, no evidence that reducing age reduces youth-offending), simply that societal interests will impact on the setting of the age of responsibility and age for consent and they may not push in the same direction.

Too often the gendered aspect of the age of consent debate is not emphasised. The first point to make is that the societal and relational pressures within which autonomy is exercised are fundamentally different from boys and girls. ${ }^{58}$ Second, heterosexual intercourse carries with it far more risks for women than men, especially given the relatively low use of contraception typically during first intercourse (around 10 per cent of young people used no contraception when the parties first had sex). ${ }^{59}$ As Beresford points out:

... the medical risks attendant for young teenage pregnancy includes low birth weight, premature labor, anemia, and pre-eclampsia. World Health Organization (WHO) research demonstrates that girls giving birth aged 14 or younger are five times as likely to die, and that stillbirths and new-born deaths are $50 \%$ higher among infants of adolescent mothers than among infants of women aged 2029 years. ${ }^{60}$

Beresford also highlights the social and economic risks of early sexual pregnancy including impacts on education and socio-economic well-being. This means that the dangers of setting the age of consent too low would fall disproportionately on girls. Third, the vast majority of young people who interact with the criminal justice system are men. So considering the impact on the lives of young people caused by the setting of the age of criminal responsibility also has significant gender dimensions.

55 Ibid 13.

56 Ray Arthur, 'Rethinking the Criminal Responsibility of Young People in England and Wales' (2012) 20 European Journal of Crime, Criminal Law and Criminal Justice 13.

$57 \operatorname{Re} G$ [2008] UKHL 37 [55].

58 Herring (n 9).

59 Kaye Wellings, Kiran Nanchahal, Wendy Macdowall, Sally McManus, Bob Erens, Catherine H Mercer, Anne M Johnson, Andrew J Copas, Christos Korovessis, Kevin A Fenton and Julia Field, 'Sexual Behaviour in Britain: Early Heterosexual Experience' (2001) 358 The Lancet 1843.

60 Beresford (n 15). 


\section{Conclusion}

This article has sought to highlight how very different are the issues which should be considered when determining the age of criminal responsibility and the age of consent. It has, therefore, argued against the views of those who claim that if a child is sufficiently mature to give consent to sex it follows she is sufficiently mature to be criminally responsible for engaging in sexual activity. I have drawn on three primary arguments. The first is that consent is giving another person permission to do an act which is otherwise unjustified. While the age of criminal responsibility is determining when a person is prima facie sufficiently responsible for their acts to be answerable to them in the criminal law. These are very different matters and the law, quite properly, may put the two at different points of the age scale. The second is that a good case can be used for not using a brightline criterion based on age in relation to criminal responsibility, while such a bright-line criterion is appropriate for age to consent. Finally, I have argued that the social consequences of setting the appropriate age for consent and criminal responsibility are very different. 